\title{
The pterygoclival ligament: a novel landmark for localization of the internal carotid artery during the endoscopic endonasal approach
}

\author{
Ali Tayebi Meybodi, MD, ${ }^{1}$ Andrew S. Little, MD, ${ }^{1}$ Vera Vigo, MD, ${ }^{2}$ Arnau Benet, MD, ${ }^{1}$ \\ Sofia Kakaizada, ${ }^{2}$ and Michael T. Lawton, MD' \\ 1Department of Neurological Surgery, Barrow Neurological Institute, Phoenix, Arizona; and ${ }^{2}$ Skull Base and Cerebrovascular \\ Laboratory, University of California, San Francisco, California
}

\begin{abstract}
OBJECTIVE The transpterygoid extension of the endoscopic endonasal approach provides exposure of the petrous apex, Meckel's cave, paraclival area, and the infratemporal fossa. Safe and efficient localization of the lacerum segment of the internal carotid artery (ICA) is a crucial part of such exposure. The aim of this study is to introduce a novel landmark for localization of the lacerum ICA.

METHODS Ten cadaveric heads were prepared for transnasal endoscopic dissection. The floor of the sphenoid sinus was drilled to expose an extension of the pharyngobasilar fascia between the sphenoid floor and the pterygoid process (the pterygoclival ligament). Several features of the pterygoclival ligament were assessed. In addition, 31 dry skulls were studied to assess features of the bony groove harboring the pterygoclival ligament.

RESULTS The pterygoclival ligament was identified bilaterally during drilling of the sphenoid floor in all specimens. The ligament started a few millimeters posterior to the posterior end of the vomer alae and invariably extended posterolaterally and superiorly to blend into the fibrous tissue around the lacerum ICA. The mean length of the ligament was $10.5 \pm$ $1.7 \mathrm{~mm}$. The mean distance between the anterior end of the ligament and midline was $5.2 \pm 1.2 \mathrm{~mm}$. The mean distance between the posterior end of the ligament and midline was $12.3 \pm 1.4 \mathrm{~mm}$. The bony pterygoclival groove was identified at the confluence of the vomer, pterygoid process of the sphenoid, and basilar part of the occipital bone, running from posterolateral to anteromedial. The mean length of the groove was $7.7 \pm 1.8 \mathrm{~mm}$. Its posterolateral end faced the anteromedial aspect of the foramen lacerum medial to the posterior end of the vidian canal. A clinical case illustration is also provided.
\end{abstract}

CONCLUSIONS The pterygoclival ligament is a consistent landmark for localization of the lacerum ICA. It may be used as an adjunct or alternative to the vidian nerve to localize the ICA during endoscopic endonasal surgery.

https://thejns.org/doi/abs/10.3171/2017.12.JNS172435

KEYWORDS vidian nerve; vidian artery; vidian canal; transpterygoid approach; sphenoid sinus; pharyngobasilar fascia; surgical technique

$\mathrm{T}$ HE endoscopic endonasal approach (EEA) and its transpterygoid and transclival extensions have revolutionized the surgical treatment of skull base lesions. ${ }^{1,4,26-28,38,46}$ Through providing a wide panoramic view, avoidance of skin incisions, minimal bone resection, and less manipulation and retraction of neurovascular structures, the EEA has reduced complications and improved patient outcome. . $^{3,6,14,43,49}$

Despite these benefits, the shift from the classic 3D transcranial microsurgical perspective to the 2D panoram- ic endonasal view may lead to disorientation and confusion during EEA., 911,16 This becomes evident when large lesions with lateral extension obscure the natural anatomical landmarks or distort the natural course of critical structures, such as the internal carotid artery (ICA). This can result in an increased risk of ICA injury, which is the most dreaded complication of EEA.12 On the other hand, efficient localization of the ICA is a crucial step during the expanded endonasal approaches to the clivus, petrous apex, and Meckel's cave..$^{24,27-29,39}$ The incorporation of surgical

ABBREVIATIONS EEA = endoscopic endonasal approach; ICA = internal carotid artery.

SUBMITTED September 28, 2017. ACCEPTED December 5, 2017.

INCLUDE WHEN CITING Published online May 18, 2018; DOI: 10.3171/2017.12.JNS172435. 
adjuncts, such as intraoperative imaging and neuronavigation into the operative armamentarium, has facilitated this objective. 17,19,21,32,33,47 However, none of these adjuncts obviates the need for a clear and sound anatomical understanding. Specifically, a clear understanding of the ICA anatomy viewed from a ventral perspective through the EEA is the most efficient tool that enables the surgeon to proceed with confidence when dealing with lesions close to the ICA. ${ }^{23,24,29}$ Anatomical landmarks are indispensable parts of such understanding. ${ }^{2,20,31}$ Without clear and consistent anatomical landmarks, the fear of ICA injury may significantly limit the extent of surgical exploration, eventually leading to suboptimal results, while simultaneously increasing the risk of devastating ICA injury.

Many studies have tried to delineate the nuances of endoscopic ICA anatomy by providing practical surgical landmarks to efficiently localize different segments of the ICA. ${ }^{5,10,11,15,16,18-20,27-30,34-37,41,44}$ Kassam et al. introduced and popularized the vidian nerve as a safe and efficient landmark to identify the lacerum segment of the ICA. ${ }^{25-28}$ Labib et al. defined a fibrocartilaginous tissue surrounding the lacerum ICA (i.e., carotid sock), but did not investigate the surgical relevance of this structure or any other landmark to identify this tissue during EEA.$^{29}$ Localization of the lacerum ICA is of utmost importance, because it allows efficient localization of the adjacent proximal (i.e., petrous) and distal (i.e., paraclival) segments of the ICA..$^{29}$ Furthermore, identification of the lacerum and paraclival segments of the ICA enables localization of other structures, such as the adjacent nerves in the cavernous sinus. ${ }^{11}$ However, the surgical exposure of the ICA through the identification of the vidian nerve may involve sacrifice of the nerve, leading to loss of lacrimation and subsequent ophthalmic complications. ${ }^{39}$ Moreover, when the vidian canal is already invaded by the lesion, no other safe and consistent landmark seems to exist for efficient localization of the ICA.

In this anatomical study, we introduce a novel landmark to localize the lacerum segment of the ICA, which we term the pterygoclival ligament. Through a series of cadaveric dissections and dry skull studies, we sought to delineate the various anatomical features of this landmark and evaluate its efficiency in consistently localizing the lacerum segment of the ICA.

\section{Methods \\ Cadaver Study}

Ten cadaveric heads (20 sides) were prepared for dissection using our embalming formula? Endoscopic endonasal dissections were carried out using $0^{\circ}$ and $30^{\circ}$ rigid endoscopes (Stryker). Distances and angles were measured using a stereotactic navigation system (iNtellect Cranial Navigation System, Stryker).

\section{Dissection Protocol}

Each head was fixed using a 3-pin head clamp (Mizuho America) in the supine position such that the nasal dorsum was almost parallel to the floor. An endoscopic binostril approach was carried out in all specimens to reach and explore the sphenoid sinus and pterygoid region. The

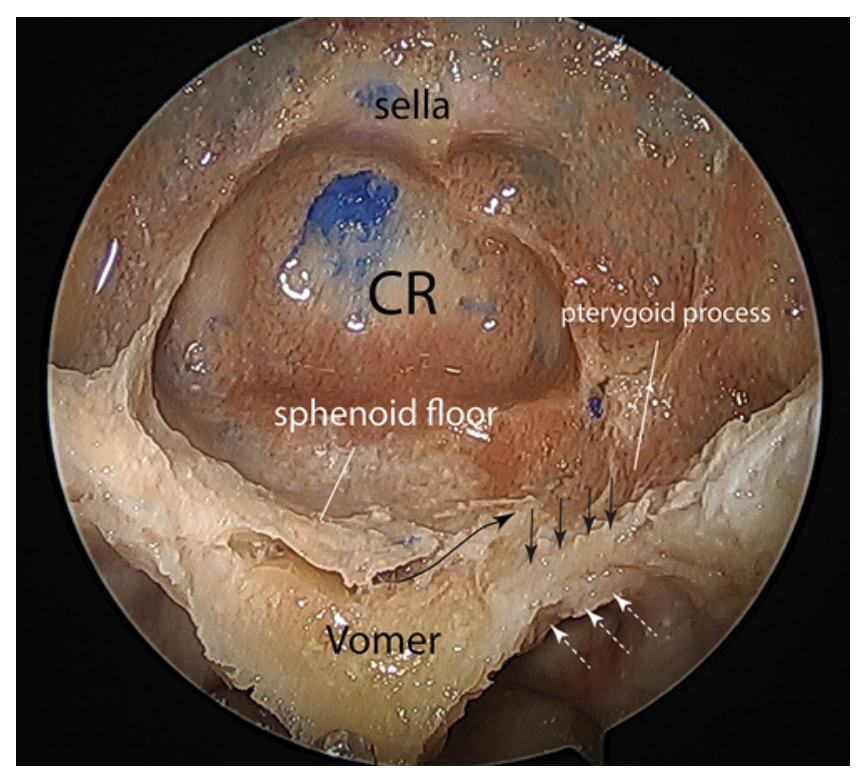

FIG. 1. Exposure of the pharyngobasilar fascia (straight black arrows) between the pharyngeal mucosa (dashed white arrows) and the floor of the sphenoid sinus, as the drilling is continued on the left sphenoid floor (view from a $30^{\circ}$ endoscope). Posterior to the junction of the vomer with the sphenoid body, a thick extension of the pharyngobasilar fascia appears between the sphenoid floor medially and the pterygoid process laterally (curved black arrow). CR = clival recess. Copyright Michael T. Lawton. Published with permission. Figure is available in color online only.

transnasal approach started with bilateral middle turbinectomies and localization of the bilateral sphenopalatine foramina. Next, a posterior septectomy was performed while the alae of the vomer were kept attached to the sphenoid bone. Bilateral posterior ethmoidectomies and sphenoidotomies were also performed. Next, the pterygopalatine fossa was exposed just posterior to the sphenopalatine foramen to find the anterior end of the vidian canal. Using a high-speed drill (Medtronic), the inferior parts of the sphenoidotomies were enlarged while drilling from medial to lateral. Drilling continued on the floor of the sphenoid sinus in a medial-to-lateral direction posterior to the attachment of the vomer. Such drilling revealed the pharyngobasilar fascia between the nasopharyngeal mucosa and the floor of the sphenoid sinus. A few millimeters posterior to the attachment of the vomer to the sphenoid body, a thickened extension of the pharyngobasilar fascia (i.e., the pterygoclival ligament) was found as an elevated ridge of fibrous tissue between the pterygoid process (laterally) and the floor of the sphenoid sinus (medially) (Fig. 1). This ligament extended posteriorly from the junction between the posterior end of the vomer and the pterygoid process. Drilling on either side of this ligament, which coursed from anteromedial to posterolateral, led to the anteromedial aspect of the lacerum segment of the ICA (Fig. 2 and Video 1).

VIDEO 1. Cadaveric surgical simulation video demonstrating the technique of exposing the pterygoclival ligament as a means of localizing the lacerum segment of the ICA during the endoscopic endonasal approach. Copyright Michael T. Lawton. Published with permission. Click here to view. 

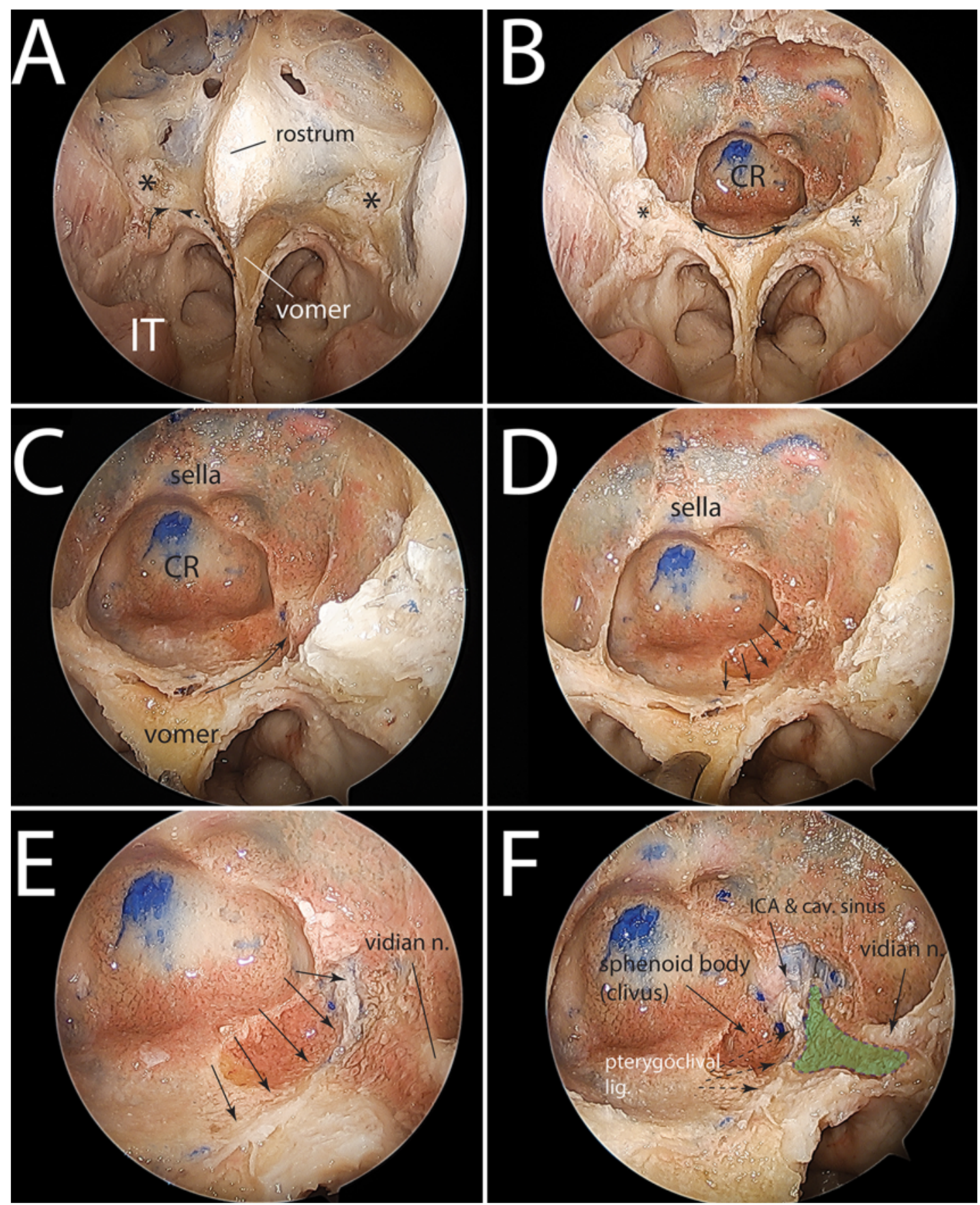

FIG. 2. Cadaveric dissection depicting the steps to expose the pterygoclival ligament and the lacerum segment of the ICA.

A: Completed posterior septectomy and bilateral middle turbinectomies, leading to exposure of the sphenoid rostrum. Asterisks designate the sphenopalatine foramina. B: Bilateral sphenoidotomies have been completed. To expose the pterygoclival ligaments bilaterally, the floor of the sphenoid sinus should be drilled in a medial-to-lateral fashion (double curved arrow), starting just posterior to the junction of the vomer and sphenoid body, extending posteriorly. Asterisks designate the sphenopalatine foramina. C: Immediately posterior to the junction of the vomer with the sphenoid body, the pterygoclival ligament is exposed (curved arrow), extending posterolaterally. D: Drilling on top of the pterygoclival ligament and on either side of it enables its following toward the lateral clivus (arrows). E: Extending posteriorly, the pterygoclival ligament starts to assume an ascending trajectory (arrows). This change in the trajectory of the ligament signifies its merging into the fibrous tissue surrounding the lacerum segment of the ICA. F: The lacerum and early cavernous segments of the ICA are exposed using the pterygoclival ligament as the landmark. Note the location of the ligament between two bony regions: the sphenoid body (clivus) and the pterygoid process (green area). Also note the relationship between the pterygoclival ligament (marked by dashed arrows) and the vidian nerve as they lead to the ICA. cav. = cavernous; $\mathrm{CR}=$ clival recess; $\mathrm{IT}=$ inferior turbinate; lig. = ligament; $\mathrm{n}$. = nerve. $\mathrm{A} 0^{\circ}$ endoscope was used in panels $\mathrm{A}$ and $\mathrm{B}$. A $30^{\circ}$ endoscope was used in panels $\mathrm{C}-\mathrm{F}$. Copyright Michael T. Lawton. Published with permission. Figure is available in color online only. 

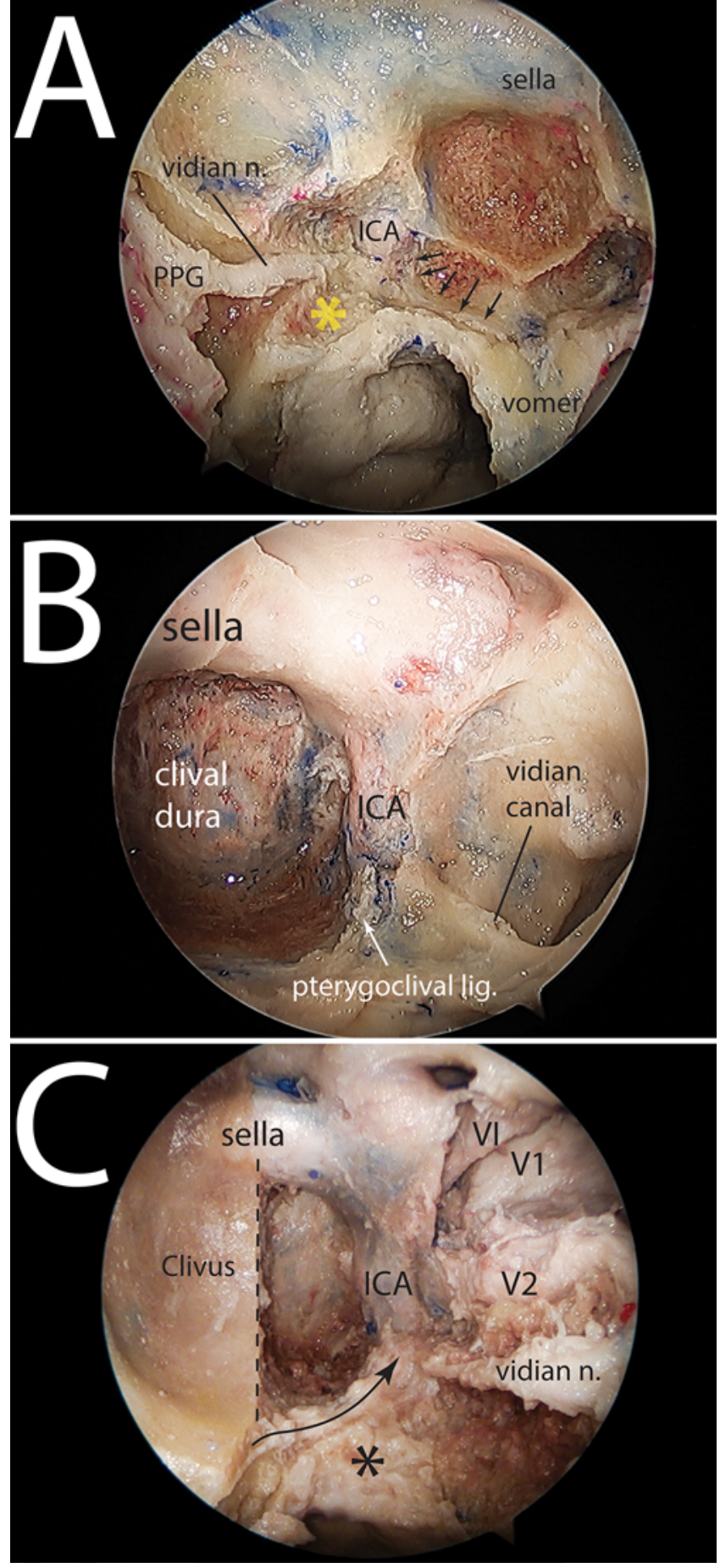

FIG. 3. Relationship between the pterygoclival ligament and the vidian nerve ( $30^{\circ}$ endoscope views). A: The vidian canal has been unroofed on the right side as it leads to the lacerum ICA posteriorly. The pterygoclival ligament has been exposed on the same side (black arrows). Note that the vidian nerve reaches the anterolateral aspect of the lacerum ICA, whereas the pterygoclival ligament points to the anteromedial aspect of the lacerum ICA; i.e., the pterygoclival ligament reaches the ICA at a point medial to the vidian nerve. Also note the bony island between the ligament and the vidian nerve (yellow asterisk) that is formed by the pterygoid process. B: The pterygoclival ligament and the vidian canal exposed in another specimen. Note how the pterygoclival assumes an ascending trajectory once it is in proximity of the ICA.

FIG. 3. (continued) $\rightarrow$
The ligament was followed posteriorly as it merged into the fibrocartilage tissue covering the anterior aspect of the ICA at the foramen lacerum.

Using the high-speed drill, the vidian canal was also unroofed from anterior to posterior to localize the lacerum segment of the ICA (Fig. 3) and to assess the anatomical relationship between the vidian nerve and the pterygoclival ligament.

\section{Measurements}

The following measurements and evaluations were recorded for the pterygoclival ligament: 1) length of the ligament; 2) distances from the anterior and posterior ends of the pterygoclival ligament to midline; 3 ) the anatomical relationship between the posterior point of the ligament (as it blended into the fibrous sheath around the ICA at the foramen lacerum) and the posterior end of the vidian nerve; and 4) the angle between the vidian nerve and the pterygoclival ligament.

\section{Dry Skull Study}

Thirty-one dry skulls were studied bilaterally (62 sides) to assess the bony groove harboring the pterygoclival ligament on the exocranial surface of the skull base. The length of this groove and the distance from its anterior and posterior ends to midline (designated by an imaginary line projected from the posterior portion of the vomer) were measured using a handheld caliper. The sagittal distance between the anterior end of the groove and posterior end of the alae of the vomer was also measured. Also, the anatomical relationship between the pterygoclival groove and the spheno-occipital suture was defined. Figure 4 demonstrates the measured variables during the dry skull study.

\section{Statistical Analysis}

The Student t-test was used to compare means between parametric variables; $p<0.05$ was considered to be statistically significant. Mean values are presented as the mean \pm SD.

\section{Results}

\section{Cadaver Study}

The pterygoclival ligament was identified bilaterally in all specimens regardless of the degree of sphenoid sinus aeration or the conspicuity of the paraclival carotid protuberance. It consistently ended in the fibrous tissue surrounding the lacerum segment of the ICA (Figs. 2 and 3). The ligament ran almost on the horizontal plane from anterior to posterior. However, as it became closer to the ICA, it assumed a relatively ascending trajectory and merged

FIG. 3. C: Endoscopic endonasal dissection of the left side of the sphenoid sinus in another specimen, showing the spatial relationship between the pterygoclival ligament (curved arrow) and the vidian nerve. The intracavernous nerves are also exposed. Note that the bony island between the pterygoclival ligament and the vidian nerve has been completely drilled out to expose the underlying pharyngobasilar fascia (asterisk). lig. = ligament; $\mathrm{n}$. = nerve; $\mathrm{PPG}$ = pterygopalatine ganglion; $\mathrm{V} 1$ = ophthalmic nerve; V2 = maxillary nerve; VI = abducent nerve. Copyright Michael T. Lawton. Published with permission. Figure is available in color online only. 


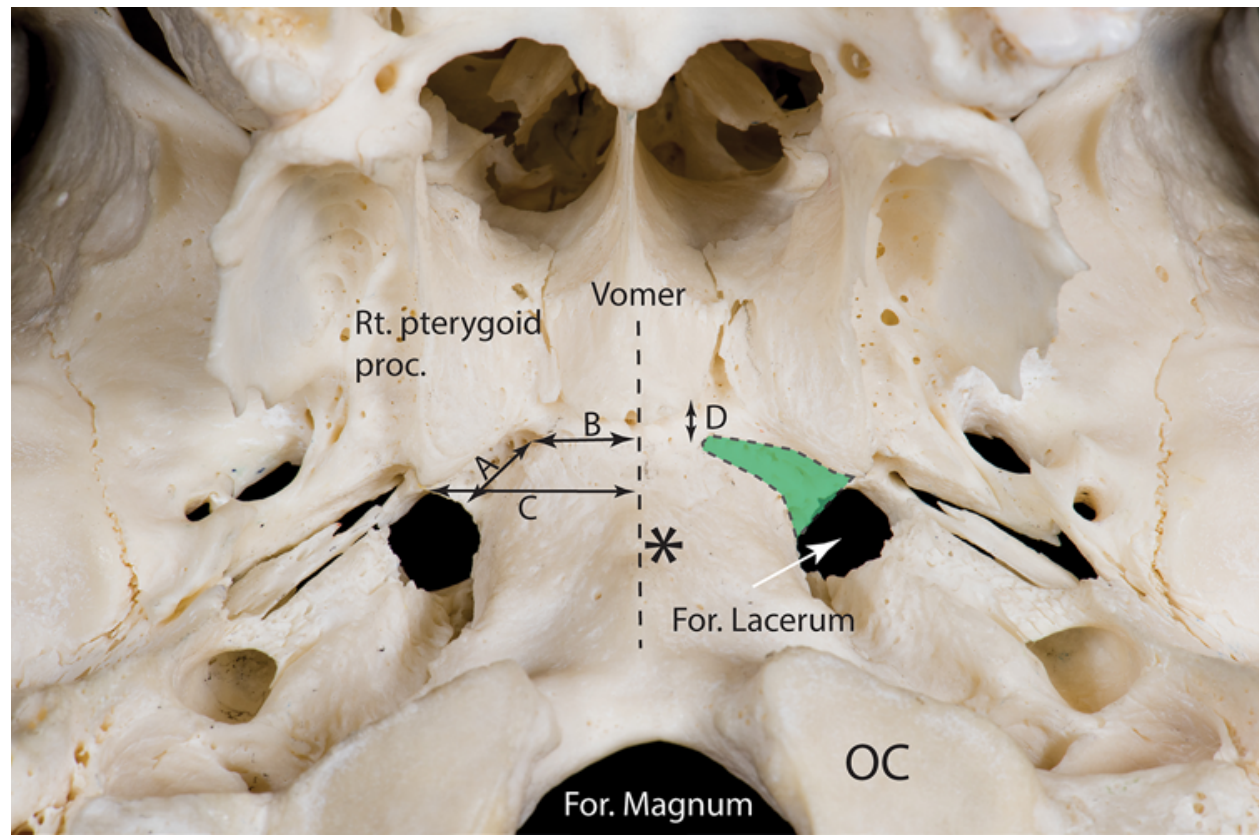

FIG. 4. Depiction of the assessed variables during the dry skull study. The green area signifies the pterygoclival groove. $A=$ length of the pterygoclival groove. $\mathrm{B}=$ distance between midline and the anterior end of the pterygoclival groove. $\mathrm{C}=$ distance between midline and the posterior end of the pterygoclival groove. $D=$ sagittal distance between the anterior end of the pterygoclival groove and the posterior end of vomer. For. $=$ foramen; $\mathrm{OC}=$ occipital condyle; proc. $=$ process; $\mathrm{Rt}$. $=$ right; ${ }^{*}=$ basilar part of the occipital bone. Copyright Michael T. Lawton. Published with permission. Figure is available in color online only.

into the fibrous tissue surrounding the lacerum segment of the ICA (Fig. 2). Therefore, the overall direction of the ligament was always from inferior, medial, and anterior to superior, lateral, and posterior. In half of the specimens, this ligament contained a venous space that communicated with the cavernous sinus superiorly and the pterygoid plexus inferior to the foramen lacerum. The mean length of the ligament was $10.5 \pm 1.7 \mathrm{~mm}$. The mean distance between the anterior end of the ligament and midline was $5.2 \pm 1.2 \mathrm{~mm}$. The mean distance from the posterior end of the ligament to midline was $12.3 \pm 1.4 \mathrm{~mm}$.

The pterygoclival ligament was consistently found between the floor of the sphenoid sinus medially and the pterygoid process medial to the vidian canal laterally (Figs. 2, 3, and 5). In all specimens, the anterior end of the ligament was located in an inferomedial position relative to the anterior end of the vidian nerve. The posterior end of the ligament was medial to the ICA attachment of the vidian nerve in all specimens (superomedial in 15 specimens [75\%] and inferomedial in 5). The mean distance between the posterior end of the ligament and the posterior end of the vidian canal was $5.9 \pm 1.6 \mathrm{~mm}$. The relative location of the most anterior point of the ligament to the anterior end of the vidian canal was inferomedial in all specimens. The mean angle formed between the pterygoclival ligament and the vidian nerve was $69.6^{\circ} \pm 4.6^{\circ}$. Table 1 lists
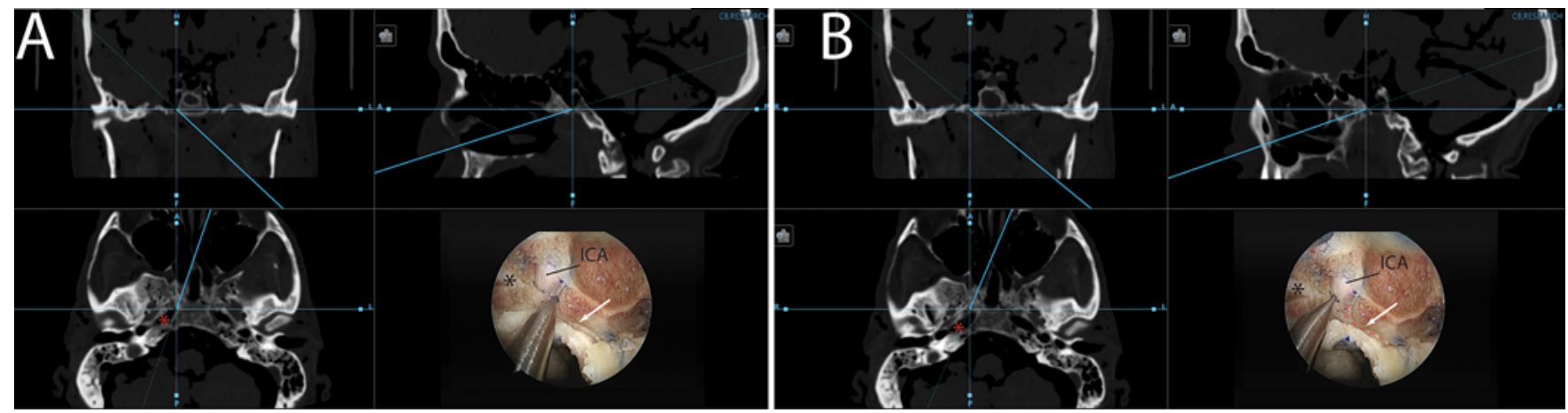

FIG. 5. Spatial relationship between the pterygoclival ligament and the vidian nerve with CT navigational verification. A: The tip of the stereotactic navigation system pointer is placed at the posterior end of the pterygoclival ligament (white arrow). B: The tip of the stereotactic navigation system pointer is placed at the posterior end of the vidian nerve (black asterisk). Stereotactic navigation confirms that the pterygoclival ligament (white arrows) ends at the anteromedial aspect of the lacerum segment of the ICA, whereas the vidian nerve (black asterisks) ends at the anterolateral aspect of the lacerum segment of the ICA. Red asterisks designate the petrous carotid canal ending at the lacerum ICA anteromedially. Figure is available in color online only. 
TABLE 1. Morphometric characteristics of the pterygoclival ligament in 10 cadaveric heads

\begin{tabular}{|c|c|c|c|c|c|}
\hline \multirow[b]{2}{*}{ Variable } & \multicolumn{2}{|c|}{ Left } & \multicolumn{2}{|c|}{ Right } & \multirow{2}{*}{$\begin{array}{c}p \\
\text { Value }\end{array}$} \\
\hline & Mean \pm SD & Range & Mean \pm SD & Range & \\
\hline Length of the pterygoclival ligament & $10.7 \pm 1.8$ & $7.6-13.2$ & $10.3 \pm 1.8$ & $6.5-12.6$ & 0.34 \\
\hline Anterior end to midline & $5.1 \pm 0.8$ & $3.7-6.2$ & $5.4 \pm 1.5$ & $3.6-7.5$ & 0.27 \\
\hline Posterior end to midline & $11.9 \pm 1.4$ & $9.6-13.8$ & $12.8 \pm 1.3$ & $10.8-14.7$ & 0.09 \\
\hline Distance btwn the posterior ends of the ligament \& vidian nerve & $6.0 \pm 1.6$ & $4.3-9.4$ & $5.9 \pm 1.7$ & $3.4-8.9$ & 0.47 \\
\hline Angle btwn the ligament \& the vidian nerve (degrees) & $70.8 \pm 4.3$ & $64.0-76.4$ & $67.9 \pm 4.7$ & $62.0-75.8$ & 0.11 \\
\hline
\end{tabular}

Values are presented in millimeters unless otherwise specified.

* Student t-test to compare means between the 2 sides.

the mean values and ranges for left and right sides. No statistically significant difference was observed between measured variables for the left and right sides.

\section{Dry Skull Study}

The bony area containing the pterygoclival ligament on the exocranial surface of the skull base was a triangularshaped groove at the confluence of the vomer alae, the body and pterygoid process of the sphenoid bone, and the basilar part of the occipital bone (Fig. 6A and B). The apex of this triangular area was anteromedial, and its base was facing posterolaterally toward the foramen lacerum. When looking at the exocranial surface of the skull base from inferior, the groove ended on the foramen lacerum at 2 o'clock on the right and at 10 o'clock on the left. This groove was well visualized in all skulls. The mean length of the groove was $7.7 \pm 1.8 \mathrm{~mm}$. Its shape varied between a wide shallow groove and a thin deep notch. Upon reaching the foramen lacerum, the pterygoclival groove extended superolaterally, between the posterior surface of the sphenoid body (i.e., the clivus) and the base of the pterygoid process (Fig. 6C and $\mathrm{D})$, hence the name pterygoclival. The pterygoclival groove tapered into the carotid sulcus on the posterolateral surface of the sphenoid body, while it rested superior and lateral to the posterior end of the vidian canal (Fig. 6C). The ascending trajectory of this groove and its tapering into the anteromedial aspect of the carotid sulcus correlated with the important finding of the cadaveric study: the pterygoclival ligament assumes an ascending trajectory as it nears the ICA.

The relationship between the pterygoclival groove and spheno-occipital suture was variable. In 19 skulls (38 sides), its posterior end was at the level of the spheno-occipital suture. In 11 skulls (22 sides), the spheno-occipital suture crossed the pterygoclival groove at its midlevel. In 1 skull (2 sides), the groove was found to be just posterior to the spheno-occipital suture, with its anterior end crossing the suture. The mean distance between the anterior end of the pterygoclival groove and the midline was $6.8 \pm 1.3$ $\mathrm{mm}$. The distance between the posterolateral corner of the groove and midline was $13.6 \pm 1.6 \mathrm{~mm}$.

In 29 skulls, the anterior end of the groove was lateral and posterior to the posterolateral end of vomer alae, whereas in 1 skull ( 2 sides), it was at the same level with the posterior vomer. The mean sagittal distance between the anterior end of the pterygoclival groove and the vomer was $2.5 \pm 1.6 \mathrm{~mm}$ (parameter D in Fig. 4). Only in 1 skull, the groove extended $2.2 \mathrm{~mm}$ anterior to the posterior vomer. No statistically significant difference was found between left and right measurements (Table 2).

\section{Illustrative Case}

A 33-year-old woman with a grade I chondrosarcoma that had recurred after 3 prior transcranial resections (2009, 2011, and 2015) presented with new-onset rightsided facial pain 2 years after her latest tumor resection. The patient received no adjuvant treatment following her prior surgeries. MRI and CT angiography revealed a lesion involving the petrous bone, clivus, and Meckel's cave with inferolateral displacement of the petrous ICA (Fig. 7A-D). Given her 3 prior transcranial procedures and the presence of a midline component of the tumor, we elected to resect the tumor using an endoscopic endonasal transsphenoidal, transmaxillary, transpterygoid approach. The endonasal approach affords the advantages of utilizing a virgin surgical corridor, addresses both the medial and lateral aspects of the tumor, and provides a minimally invasive approach compared with a craniotomy. During the endoscopic exposure, the pterygoclival ligament was visualized after drilling the rostrum of the sphenoid and floor of the sphenoid sinus (Fig. 7E and F). The ligament and the vidian canal helped triangulate the location of the carotid genu at the foramen lacerum (green area in Fig. 7E). Postoperative imaging showed gross-total resection of the tumor (Fig. 7G-I).

\section{Discussion}

We report a novel anatomical landmark for localization of the ICA during EEA. Safe and correct localization of the ICA is an important step in the endoscopic treatment of skull base lesions located in proximity of the clivus, pterygoid process, and adjacent areas. ${ }^{28,29,39}$ The EEA and its various extensions enable the exposure of the entire length of ICA from its pharyngeal segment to the paraclinoid segment. ${ }^{1,4,26-28,38,42,46}$ Regardless of the specific subtype of the approach, the cardinal feature common to all these subtypes is safe and efficient ICA localization. The rate of ICA injury during endonasal surgery can range from $0.2 \%$ to $1.4 \%$ based on surgeon's experience. . $^{8,13,17,29,45}$ In spite of being uncommon, ICA injury is one of the most fearsome and debilitating complications. The risk of ICA injury is not eliminated even with the use of endoscopic Doppler or neuronavigation..$^{17,32,48}$ Although the protuberance of the 

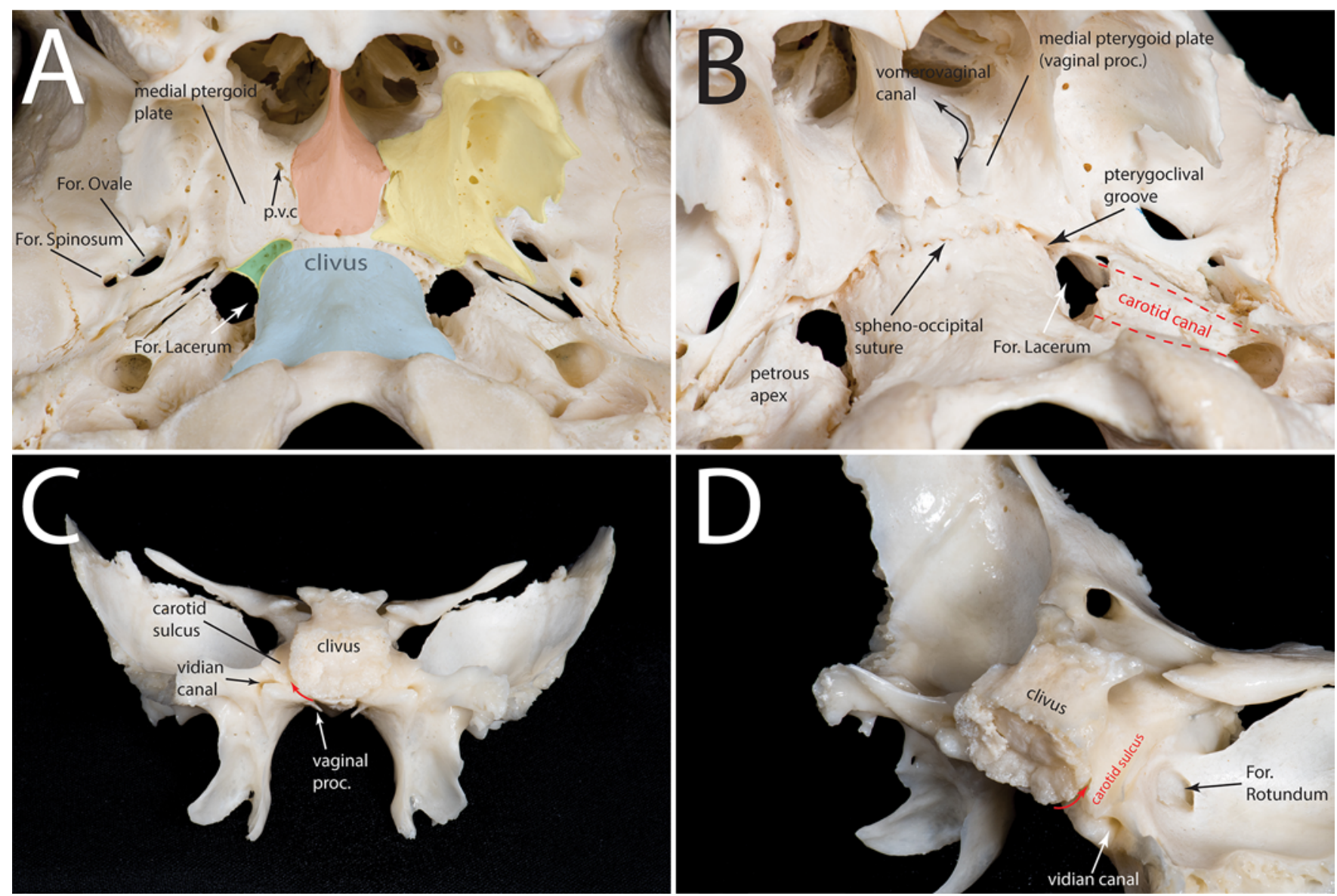

FIG. 6. Bony characteristics of the pterygoclival groove. A: Inferior view of the exocranial surface showing the bilateral pterygoclival grooves (green area) leading to the lacerum foramina at their posterior end. The pterygoclival groove is bordered by 3 bones: 1) the vomer (red), 2) the pterygoid part of the sphenoid bone (yellow), and 3) the clivus (formed by the sphenoid body and basilar part of the occipital bone; light blue). B: Oblique view of the same skull in panel A, showing the relationship between the pterygoclival groove and foramen lacerum. The relationship between the pterygoclival groove and the spheno-occipital groove is variable. However, in the majority of specimens it was found to cross the posterior end of the groove or its midlevel. C: Posterior view of the sphenoid bone showing the relationship between the pterygoclival groove (red arrow) and the carotid sulcus located on the posterolateral aspect of the sphenoid body. Note the ascending trajectory of the pterygoclival groove at the point of reaching the carotid sulcus. Also note the relative location of the posterior end of the vidian canal and the pterygoclival groove. D: Right posterior oblique view of the sphenoid bone, depicting the relative location of the pterygoclival groove (red arrow), the carotid sulcus, and the posterior end of the vidian canal. For. = foramen; proc. = process; p.v.c = palatovaginal canal. Copyright Michael T. Lawton. Published with permission. Figure is available in color online only.

paraclival ICA is visible in many cases after exposure of the contents of the sphenoid sinus, with poorly pneumatized sinuses, the localization of the ICA becomes difficult. Even with well-pneumatized sinuses, the paraclival
ICA protuberance may be missing in $30 \%-50 \%$ of cases. ${ }^{32,48}$ Also, the carotid protuberance could lie medial or lateral to the paraclival ICA, which could be misleading.48

The vidian canal is an excellent landmark to localize

\section{TABLE 2. Morphometric characteristics of the pterygoclival groove in 31 cadaveric dry skulls}

\begin{tabular}{|c|c|c|c|c|c|}
\hline \multirow[b]{2}{*}{ Variable* } & \multicolumn{2}{|c|}{ Left } & \multicolumn{2}{|c|}{ Right } & \multirow{2}{*}{$\begin{array}{c}p \\
\text { Value }\end{array}$} \\
\hline & Mean \pm SD & Range & Mean \pm SD & Range & \\
\hline Length of the pterygoclival groove (A) & $7.7 \pm 2.0$ & $4.3-13.2$ & $7.5 \pm 1.7$ & $4.5-11.6$ & 0.36 \\
\hline Anterior end to midline (B) & $6.7 \pm 1.4$ & $4.1-9.8$ & $6.9 \pm 1.1$ & $4.9-9.6$ & 0.22 \\
\hline Posterior end to midline (C) & $13.3 \pm 1.4$ & $10.8-15.8$ & $13.8 \pm 1.6$ & $10.5-17.0$ & 0.1 \\
\hline Sagittal distance btwn the anterior end of the groove \& posterior vomer (D) & $2.5 \pm 0.9$ & $0-6.7$ & $2.4 \pm 0.8$ & $0-7.3$ & 0.37 \\
\hline
\end{tabular}

Values are presented in millimeters unless otherwise specified.

* See Fig. 4 for an illustrative depiction of the measured variables.

$\dagger$ Student t-test to compare means between 2 sides. 

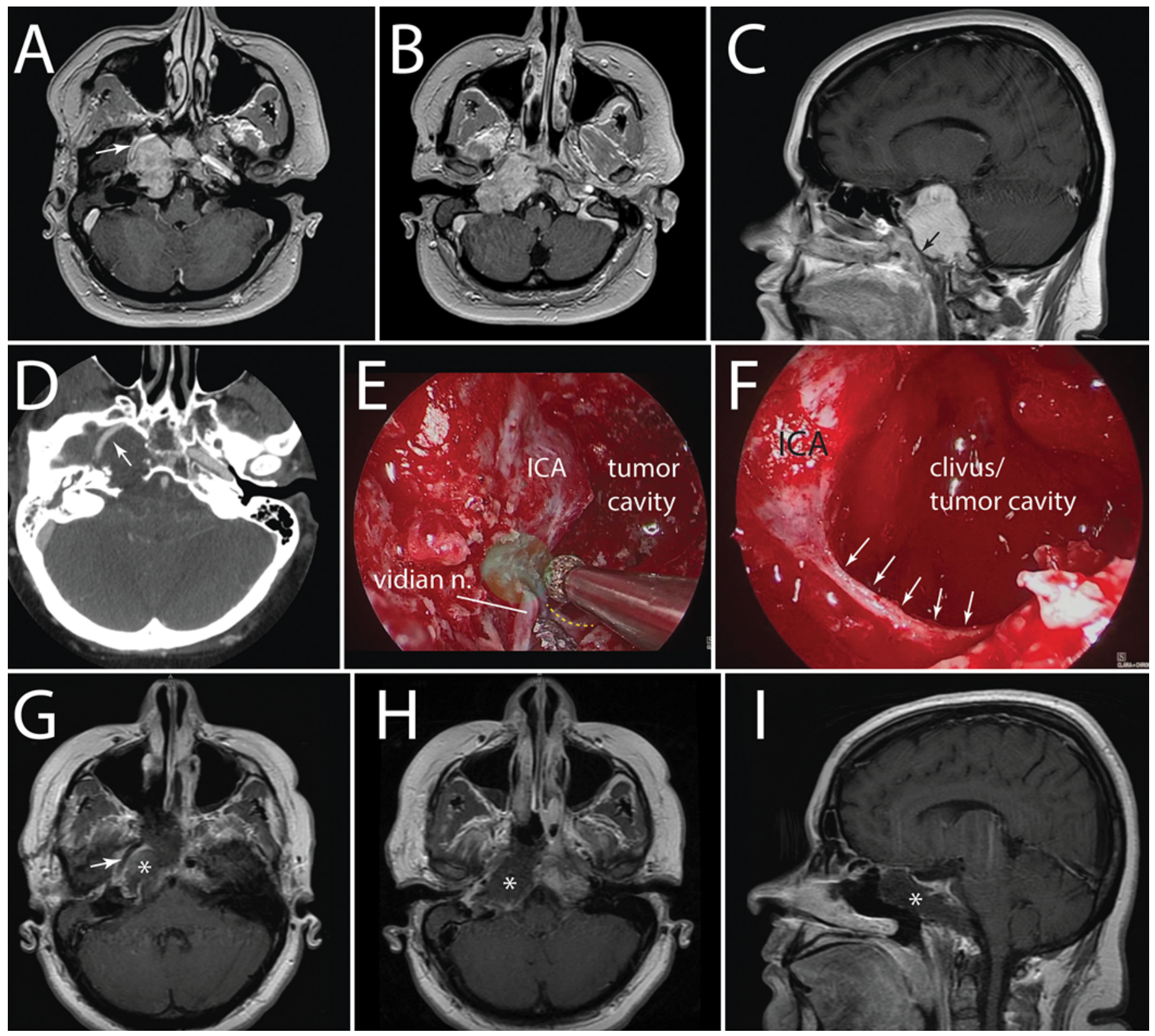

FIG. 7. Case illustration showing a recurrent grade I chondrosarcoma after 3 prior transcranial resections $(2009,2011$, and 2015) in a 33-year-old woman. She received no adjuvant treatment. A-D: MRI scans (A-C) and CT angiogram (D) revealing a recurrent lesion involving the petrous bone, clivus, and Meckel's cave with inferolateral displacement of the petrous ICA (arrows in A, C, and $D)$. $E$ and $F$ : The pterygoclival ligament is visualized after drilling the rostrum of the sphenoid bone and floor of the sphenoid sinus $\left(30^{\circ}\right.$ endoscope). It can be seen traversing from the midline to the anteromedial aspect of the carotid genu coalescing with the contents of the vidian canal (dashed yellow line in panel $\mathrm{E}$ and small white arrows in panel $\mathrm{F}$ ). The ligament and the vidian canal help triangulate the location of the carotid genu at the foramen lacerum (green area in panel E). G-I: Postoperative axial ( $G$ and $\mathrm{H}$ ) and sagittal (I) MRI scans demonstrating aggressive debulking of the tumor (asterisk in I) and skeletonizing of the carotid artery (arrow in G). ICA = internal carotid artery; $n$. = nerve. Figure is available in color online only.

the lacerum ICA. ${ }^{27,28,36,44}$ It runs posterolaterally from its anterior end and reaches the anterolateral part of the foramen lacerum. As drilling the pterygoid process is a necessary maneuver in exposing the more proximal segments of the ICA, exposure of the vidian nerve does not necessarily add to surgical time and burden. However, the vidian nerve is usually sacrificed during this approach, ${ }^{27,28,46}$ which may cause complications. ${ }^{36,39,40}$ A lacrimation defect caused by the sacrifice of the vidian nerve superimposed on a previously defective corneal sensation caused by a tumor can lead to devastating ophthalmic complications. Furthermore, when the vidian canal is already invaded by the tumor, lack of any consistent landmark to localize the ICA renders tumor resection extremely risky. ${ }^{47,48}$ Therefore, when possible, efficient ICA localization prior to the commencement of tumor resection is important.

The pterygoclival ligament is a structure that is naturally encountered while drilling the floor of the sphenoid 

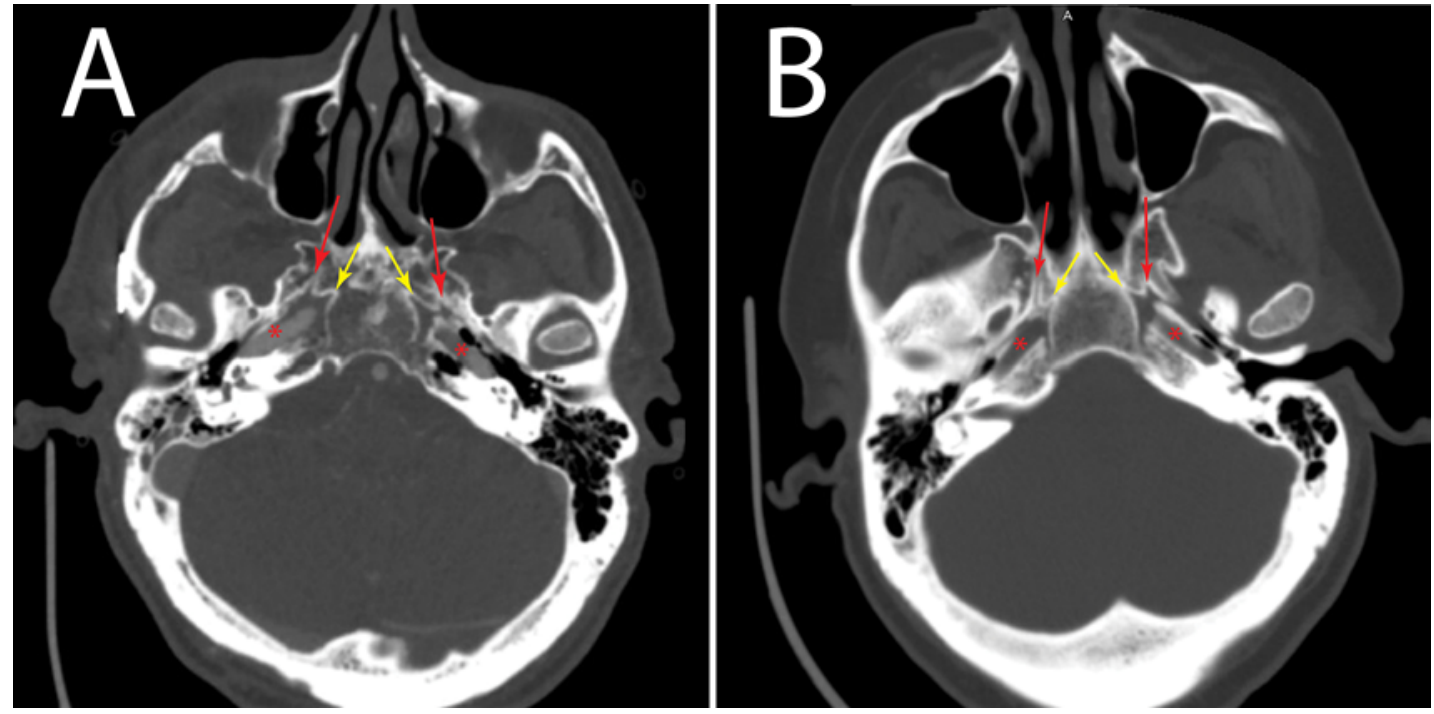

FIG. 8. Skull base CT angiogram (A) and noncontrast bone window CT scan (B) showing the relationship between the pterygoclival groove (yellow arrows) and the vidian canal (red arrows). The pterygoclival groove extends between the clivus medially and the pterygoid process of the sphenoid bone laterally. Red asterisks designate the petrous portion of the ICA. Note the medial relationship of the pterygoclival groove to the vidian canal. Figure is available in color online only.

sinus during transclival or transpterygoid approaches. It is a fibrous structure lying between two bony regions: 1) the pterygoid process and 2) the sphenoid body (Figs. 2, 3, and 6). This ligament is an extension of the pharyngobasilar fascia that continues posteriorly to reach the anteromedial aspect of the foramen lacerum, marking the lacerum segment of the ICA. The fibrocartilaginous plug that fills the exocranial end of the foramen lacerum ${ }^{16,19,29}$ extends superiorly to invest the lacerum ICA and is continuous anteromedially with the pterygoclival ligament and the pharyngobasilar fascia (Fig. 2). The pharyngobasilar fascia (also referred to as the pharyngeal aponeurosis) is a thick fibrous tissue that underlies and supports the pharyngeal mucosa. It extends superiorly from the superior pharyngeal constrictor muscle, attaching to the basal surfaces of the occipital and sphenoid bones. ${ }^{22}$ Its anterior limit is at the medial pterygoid plates. ${ }^{22}$ At the inferior surface of the sphenoid body, where there is no muscle attaching, the fascia lies between the mucosa and the bone (Figs. 1 and 3C). The pterygoclival ligament is a bilateral focal thickening of the pharyngobasilar fascia at the pterygoclival groove. When the floor of the sphenoid sinus is drilled, this ligamentous structure becomes evident about 2.1-2.9 $\mathrm{mm}(95 \% \mathrm{CI})$ posterior to the posterior end of the vomer. It is important to note that the pterygoclival ligament blends into the pharyngobasilar fascia anteriorly, which may cause it to become somewhat inconspicuous. However, as drilling is continued posteriorly and laterally, the ligament is clearly seen as an elongated fibrous tissue between the pterygoid process laterally and the sphenoid floor medially. The bony region lateral to the pterygoclival ligament is the part of the pterygoid process medial to the vidian canal (Figs. 2F and $3 \mathrm{~A}$ ).

The pterygoclival ligament has not been previously defined as a landmark for endoscopic localization of the lacerum ICA. Labib et al. elaborated on landmarks for localization of different segments of the ICA..$^{29}$ They emphasized the use of the vidian canal to find the lacerum foramen. They also described a fibrocartilaginous tissue surrounding the lacerum segment of the ICA (the carotid sock) as an extension of the pharyngobasilar fascia. ${ }^{29} \mathrm{Al}-$ though the carotid sock is the point of posterior attachment of the pterygoclival ligament to the lacerum ICA, it is in an anatomically different position. The carotid sock surrounds the lacerum segment of the ICA at the foramen lacerum, whereas the pterygoclival ligament is an extended structure at the base of the sphenoid sinus that finally attaches to the carotid sock posteriorly. Such description of the pterygoclival ligament course and relationships is absent in the study by Labib et al. ${ }^{29}$

As a landmark for ICA localization, the pterygoclival ligament has several advantages over the vidian canal. First, it is a noneloquent structure. Although the vidian nerve is usually sacrificed without complications, problems with lacrimation may ensue after its sacrifice. ${ }^{39}$ Second, the pterygoclival groove could easily be identified on preoperative imaging with its dimensions and relationships observed. Such imaging data may indirectly provide the surgeon with the degree of prominence of the pterygoclival ligament during surgery (e.g., a large and deep pterygoclival groove may signify a readily identifiable ligament). Additionally, its location may be appraised relative to the vidian canal (Fig. 8). Furthermore, when the vidian nerve is not available as a landmark because of tumor invasion, the pterygoclival ligament can serve as a reliable alternative. However, the most important advantage of the use of pterygoclival ligament is its relative safety compared with the vidian nerve. Kassam et al. and others reported the location of the posterior end of the vidian canal to be inferolateral to the lacerum ICA. ${ }^{23,24,28,36,44}$ Kassam et al. emphasized that because of this anatomical topography, when drilling is carried out along the inferior and medial aspects of the vidian canal, the ICA is kept safe. ${ }^{28}$ However, if one assumes the vidian canal to end on the inferolateral aspect of the lacerum ICA, then any drill- 
ing medial to this canal would put the ICA at risk. Therefore, the vidian canal may not entirely be a safe landmark. On the other hand, the pterygoclival ligament ends on the anteromedial aspect of the lacerum segment of the ICA. In fact, in all specimens tested in the current study, the trajectory of the pterygoclival ligament pointed directly to the anteromedial aspect of the lacerum ICA. Therefore, when drilling is carried out from medial to lateral to expose this ligament, the ICA can be efficiently and safely localized. Furthermore, as the posterior end of the ligament ascends to merge into the carotid sock, the surgeon is further alerted by the change in the trajectory of the ligament; i.e., when close to the ICA, the ligament starts to ascend. Also, the fibrous tissue covering the anteromedial aspect of this segment of the ICA may work as an extra safety measure while drilling is continued posteriorly.

It is important to note that the ligament may contain a venous space. This venous compartment is in contact with the cavernous sinus superiorly and the pterygoid venous plexus posteroinferiorly. When present, this venous compartment can further help the surgeon identify the ligament while drilling is performed at the floor of the sphenoid sinus.

\section{Study Limitations}

This study has several limitations. First, adequate clinical data are required to ensure the easy localization of the pterygoclival ligament during surgery, despite our findings that suggest its easy identification between two bony regions along the floor of the sphenoid sinus. Second, although our study included cadaveric heads with different amounts of sphenoid sinus pneumatization, the reliability of the pterygoclival ligament in the localization of the lacerum ICA needs to be tested during live surgeries with different degrees of conspicuity of the paraclival carotid protuberances.

\section{Conclusions}

The pterygoclival ligament is a consistent and reliable landmark to localize the lacerum segment of the ICA during endoscopic endonasal surgery. It may be used as an adjunct or alternative to the vidian canal for ICA localization. It is theoretically safer as a landmark than the vidian canal is, considering its topographic location relative to the lacerum ICA. The clinical applicability of this landmark and its reliability during surgery are subject to further studies.

\section{Acknowledgments}

We thank Marie Clarkson from Neuroscience Publications at Barrow Neurological Institute for helping with the video preparation.

\section{References}

1. Abuzayed B, Tanriover N, Gazioglu N, Akar Z: Extended endoscopic endonasal approach to the clival region. J Craniofac Surg 21:245-251, 2010

2. Aktas U, Yilmazlar S, Ugras N: Anatomical restrictions in the transsphenoidal, transclival approach to the upper clival region: a cadaveric, anatomic study. J Craniomaxillofac Surg 41:457-467, 2013
3. Al-Mefty O, Kadri PA, Hasan DM, Isolan GR, Pravdenkova S: Anterior clivectomy: surgical technique and clinical applications. J Neurosurg 109:783-793, 2008

4. Al-Nashar IS, Carrau RL, Herrera A, Snyderman CH: Endoscopic transnasal transpterygopalatine fossa approach to the lateral recess of the sphenoid sinus. Laryngoscope 114:528532,2004

5. Alfieri A, Jho HD, Schettino R, Tschabitscher M: Endoscopic endonasal approach to the pterygopalatine fossa: anatomic study. Neurosurgery 52:374-380, 2003

6. Bao X, Deng K, Liu X, Feng M, Chen CC, Lian W, et al: Extended transsphenoidal approach for pituitary adenomas invading the cavernous sinus using multiple complementary techniques. Pituitary 19:1-10, 2016

7. Benet A, Rincon-Torroella J, Lawton MT, González Sánchez JJ: Novel embalming solution for neurosurgical simulation in cadavers. J Neurosurg 120:1229-1237, 2014

8. Berker M, Hazer DB, Yücel T, Gürlek A, Cila A, Aldur M, et al: Complications of endoscopic surgery of the pituitary adenomas: analysis of 570 patients and review of the literature. Pituitary 15:288-300, 2012

9. Cappabianca P, Magro F: The lesson of anatomy. Surg Neurol 71:597-599, 2009

10. Cavallo LM, Cappabianca P, Galzio R, Iaconetta G, de Divitiis E, Tschabitscher M: Endoscopic transnasal approach to the cavernous sinus versus transcranial route: anatomic study. Neurosurgery 56 (2 Suppl):379-389, 2005

11. Cebula H, Kurbanov A, Zimmer LA, Poczos P, Leach JL, De Battista JC, et al: Endoscopic, endonasal variability in the anatomy of the internal carotid artery. World Neurosurg 82:e759-e764, 2014

12. Chin OY, Ghosh R, Fang CH, Baredes S, Liu JK, Eloy JA: Internal carotid artery injury in endoscopic endonasal surgery: a systematic review. Laryngoscope 126:582-590, 2016

13. Ciric I, Ragin A, Baumgartner C, Pierce D: Complications of transsphenoidal surgery: results of a national survey, review of the literature, and personal experience. Neurosurgery 40:225-237, 1997

14. Cote DJ, Wiemann R, Smith TR, Dunn IF, Al-Mefty O, Laws ER: The expanding spectrum of disease treated by the transnasal, transsphenoidal microscopic and endoscopic anterior skull base approach: a single-center experience 2008-2015. World Neurosurg 84:899-905, 2015

15. de Lara D, Ditzel Filho LF, Prevedello DM, Carrau RL, Kasemsiri P, Otto BA, et al: Endonasal endoscopic approaches to the paramedian skull base. World Neurosurg 82 (6 Suppl):S121-S129, 2014

16. DePowell JJ, Froelich SC, Zimmer LA, Leach JL, Karkas A, Theodosopoulos PV, et al: Segments of the internal carotid artery during endoscopic transnasal and open cranial approaches: can a uniform nomenclature apply to both? World Neurosurg 82 (6 Suppl):S66-S71, 2014

17. Dusick JR, Esposito F, Malkasian D, Kelly DF: Avoidance of carotid artery injuries in transsphenoidal surgery with the Doppler probe and micro-hook blades. Neurosurgery 60 (4 Suppl 2):322-329, 2007

18. Elhadi AM, Zaidi HA, Yagmurlu K, Ahmed S, Rhoton AL Jr, Nakaji P, et al: Infraorbital nerve: a surgically relevant landmark for the pterygopalatine fossa, cavernous sinus, and anterolateral skull base in endoscopic transmaxillary approaches. J Neurosurg 125:1460-1468, 2016

19. Fortes FS, Pinheiro-Neto CD, Carrau RL, Brito RV, Prevedello DM, Sennes LU: Endonasal endoscopic exposure of the internal carotid artery: an anatomical study. Laryngoscope 122: 445-451, 2012

20. Funaki T, Matsushima T, Peris-Celda M, Valentine RJ, Joo W, Rhoton AL Jr: Focal transnasal approach to the upper, middle, and lower clivus. Neurosurgery 73 (2 Suppl Operative):ons155-ons191, 2013 
21. Gardner PA, Kassam AB, Rothfus WE, Snyderman CH, Carrau RL: Preoperative and intraoperative imaging for endoscopic endonasal approaches to the skull base. Otolaryngol Clin North Am 41:215-230, vii, 2008

22. Gray H, Standring S, Ellis H, Berkovitz BKB: Gray's Anatomy: The Anatomical Basis of Clinical Practice, ed 39. Edinburgh: Elsevier Churchill Livingstone, 2005

23. Herzallah IR, Casiano RR: Endoscopic endonasal study of the internal carotid artery course and variations. Am J Rhinol 21:262-270, 2007

24. Jouanneau E, Simon E, Jacquesson T, Sindou M, Tringali S, Messerer M, et al: The endoscopic endonasal approach to the Meckel's cave tumors: surgical technique and indications. World Neurosurg 82 (6 Suppl):S155-S161, 2014

25. Kassam A, Snyderman CH, Mintz A, Gardner P, Carrau RL: Expanded endonasal approach: the rostrocaudal axis. Part II. Posterior clinoids to the foramen magnum. Neurosurg Focus 19(1):E4, 2005

26. Kassam AB, Gardner P, Snyderman C, Mintz A, Carrau R: Expanded endonasal approach: fully endoscopic, completely transnasal approach to the middle third of the clivus, petrous bone, middle cranial fossa, and infratemporal fossa. Neurosurg Focus 19(1):E6, 2005

27. Kassam AB, Prevedello DM, Carrau RL, Snyderman CH, Gardner P, Osawa S, et al: The front door to Meckel's cave: an anteromedial corridor via expanded endoscopic endonasal approach- technical considerations and clinical series. Neurosurgery 64 (3 Suppl):ons71-ons73, 2009

28. Kassam AB, Vescan AD, Carrau RL, Prevedello DM, Gardner P, Mintz AH, et al: Expanded endonasal approach: vidian canal as a landmark to the petrous internal carotid artery. $\mathbf{J}$ Neurosurg 108:177-183, 2008

29. Labib MA, Prevedello DM, Carrau R, Kerr EE, Naudy C, Abou Al-Shaar H, et al: A road map to the internal carotid artery in expanded endoscopic endonasal approaches to the ventral cranial base. Neurosurgery 10 (Suppl 3):448-471, 2014

30. Lai LT, Morgan MK, Snidvongs K, Chin DC, Sacks R, Harvey RJ: Endoscopic endonasal transplanum approach to the paraclinoid internal carotid artery. J Neurol Surg B Skull Base 74:386-392, 2013

31. Lee SC, Senior BA: Endoscopic skull base surgery. Clin Exp Otorhinolaryngol 1:53-62, 2008

32. Leong JL, Batra PS, Citardi MJ: Three-dimensional computed tomography angiography of the internal carotid artery for preoperative evaluation of sinonasal lesions and intraoperative surgical navigation. Laryngoscope 115:1618-1623, 2005

33. Linsler S, Antes S, Senger S, Oertel J: The use of intraoperative computed tomography navigation in pituitary surgery promises a better intraoperative orientation in special cases. J Neurosci Rural Pract 7:598-602, 2016

34. Liu J, Pinheiro-Neto CD, Fernandez-Miranda JC, Snyderman $\mathrm{CH}$, Gardner PA, Hirsch BE, et al: Eustachian tube and internal carotid artery in skull base surgery: an anatomical study. Laryngoscope 124:2655-2664, 2014

35. Mason E, Gurrola J II, Reyes C, Brown JJ, Figueroa R, Solares CA: Analysis of the petrous portion of the internal carotid artery: landmarks for an endoscopic endonasal approach. Laryngoscope 124:1988-1994, 2014

36. Osawa S, Rhoton AL Jr, Seker A, Shimizu S, Fujii K, Kassam AB: Microsurgical and endoscopic anatomy of the vidian canal. Neurosurgery 64 (5 Suppl 2):385-412, 2009

37. Peris-Celda M, Kucukyuruk B, Monroy-Sosa A, Funaki T, Valentine R, Rhoton AL Jr: The recesses of the sellar wall of the sphenoid sinus and their intracranial relationships. Neurosurgery 73 (2 Suppl Operative):ons117-ons131, 2013

38. Prevedello DM, Ditzel Filho LF, Solari D, Carrau RL, Kassam AB: Expanded endonasal approaches to middle cranial fossa and posterior fossa tumors. Neurosurg Clin N Am 21:621-635, vi, 2010

39. Prevedello DM, Pinheiro-Neto CD, Fernandez-Miranda JC, Carrau RL, Snyderman CH, Gardner PA, et al: Vidian nerve transposition for endoscopic endonasal middle fossa approaches. Neurosurgery 67 (2 Suppl Operative):478-484, 2010

40. Robinson SR, Wormald PJ: Endoscopic vidian neurectomy. Am J Rhinol 20:197-202, 2006

41. Solari D, Chiaramonte C, Di Somma A, Dell'Aversana Orabona G, de Notaris M, Angileri FF, et al: Endoscopic anatomy of the skull base explored through the nose. World Neurosurg 82 (6 Suppl):S164-S170, 2014

42. Theodosopoulos PV, Guthikonda B, Brescia A, Keller JT, Zimmer LA: Endoscopic approach to the infratemporal fossa: anatomic study. Neurosurgery 66:196-203, 2010

43. Vellutini EDAS, Balsalobre L, Hermann DR, Stamm AC: The endoscopic endonasal approach for extradural and intradural clivus lesions. World Neurosurg 82 (6 Suppl):S106S115, 2014

44. Vescan AD, Snyderman CH, Carrau RL, Mintz A, Gardner P, Branstetter B IV, et al: Vidian canal: analysis and relationship to the internal carotid artery. Laryngoscope 117:13381342, 2007

45. Weber R, Draf W, Keerl R, Schick B, Saha A: Endonasal microendoscopic pansinusoperation in chronic sinusitis. II. Results and complications. Am J Otolaryngol 18:247-253, 1997

46. Zanation AM, Snyderman CH, Carrau RL, Gardner PA, Prevedello DM, Kassam AB: Endoscopic endonasal surgery for petrous apex lesions. Laryngoscope 119:19-25, 2009

47. Zhang Q, Lv H, Chen G, Guo H: Endoscopic endonasal removal of pituitary adenomas with paraclival internal carotid artery invasion. ORL J Otorhinolaryngol Relat Spec 72:28-37, 2010

48. Zhang Y, Tian Y, Song J, Li Y, Li W: Internal carotid artery in endoscopic endonasal transsphenoidal surgery. J Craniofac Surg 23:1866-1869, 2012

49. Zhao B, Wei YK, Li GL, Li YN, Yao Y, Kang J, et al: Extended transsphenoidal approach for pituitary adenomas invading the anterior cranial base, cavernous sinus, and clivus: a single-center experience with 126 consecutive cases. J Neurosurg 112:108-117, 2010

\section{Disclosures}

Dr. Little: ownership in Kogent and Spiway.

\section{Author Contributions}

Conception and design: Tayebi Meybodi. Acquisition of data: Tayebi Meybodi, Little, Vigo, Kakaizada. Analysis and interpretation of data: Lawton, Tayebi Meybodi, Little, Benet. Drafting the article: Tayebi Meybodi, Vigo. Critically revising the article: Lawton, Tayebi Meybodi, Little, Benet. Reviewed submitted version of manuscript: all authors. Approved the final version of the manuscript on behalf of all authors: Lawton. Statistical analysis: Tayebi Meybodi, Vigo. Administrative/technical/material support: Lawton, Benet. Study supervision: Lawton.

\section{Supplemental Information \\ Videos}

Video 1. https://vimeo.com/251638624.

\section{Correspondence}

Michael T. Lawton: Barrow Neurological Institute, Phoenix, AZ. michael.lawton@barrowbrainandspine.com. 